\title{
Kaposiform hemangioendothelioma
}

INSERM

\section{Source}

INSERM. (1999). Orphanet: an online rare disease and orphan drug data base.

Kaposiform hemangioendothelioma. ORPHA:2122

Kaposiform hemangioendothelioma is a very rare, aggressive, vascular tumor

manifesting in the neonatal period or in infancy as cutaneous vascular tumors to large

infiltrative lesions. 